\title{
Sensory Integration Therapy on Social and Self Care Skills in Children with Autism
}

\author{
Megha Kukreti ${ }^{2}$, Dr. Pooja varma ${ }^{2}$
}

\section{ABSTRACT:}

Autism is a lifelong neurological disability, usually appearing during the first three years of life, which severely impairs the person's sensory processing; verbal and nonverbal communication; and social interaction. Autism causes disturbance in Sensory processing which affects all areas of life like development, behaviour, learning, communication, friendships and play. The aim accentuates how Sensory Integration Therapy helps in improving the social and self care skills in children with autism (3-12 years of age). The findings reported that sensory integration therapy for three times a week for three months helps in improving some aspects of their social and self care skills. The present research provides an opportunity for further research on other types of adaptive behaviour.

Keywords: Autism, Social skills, Self Care Skills, Sensory Integration Therapy.

\section{INTRODUCTION:}

Autism is a lifelong neurological disability, usually appearing during the first three years of life, which severely impairs the person's sensory processing; verbal and nonverbal communication; and social interaction (APA, 2000).

Social skills are those skills which are developed so that the individuals behave according to the expectations of the society. It is developed through the child's relationship and interaction with the people.

Self care skills are components of basic activities of daily living which includes eating, toileting, bathing, dressing, grooming. Each component has its subcomponents and develops with age.

Sensory processing is the normal neurological processing process of organizing sensation for a person's everyday activity. We use sensations for our every day activity to function effectively and smoothly like academic skills, gravitational security, motor planning, postural stability etc. Our brain receives sensation through our body and surrounding; interpret it and send a response.

\footnotetext{
${ }^{1}$ Research scholar, AIBHAS, Amity University, Noida (U.P)

${ }^{2}$ Assistant Professor, AIBHAS, Amity University, Noida (U.P)
}

(C) 2015 I M Kukreti, P Verma; licensee IJIP. This is an Open Access Research distributed under the terms of the Creative Commons Attribution License (http://creativecommons.org/licenses/by/2.0), which permits unrestricted use, distribution, and reproduction in any Medium, provided the original work is properly cited. 


\section{Sensory Integration Therapy on Social and Self Care Skills in Children with Autism}

Adaptive behaviour which is impaired in autism is referred to as everyday coping with environmental demands and includes the skills of daily living that people perform for self-care and relate to others.

The American Association on Mental Retardation (AAMR, 1992) emphasize 10 areas of adaptive behaviours Communication, Community Use, Functional Academics, Home Living, Health and Safety, Leisure, Self-Care, Self-Direction, Social and Work.

Sensory processing disorder (SPD), also called sensory integrative dysfunction, occurs when the brain is unable to process the sensory information efficiently. The person has difficulty in responding in an appropriate manner to everyday sensation; which others hardly notice or simply take few seconds like a child who is under responsive to touch does not feel pain and thus unable to recognise the threat for e.g., touching a warm utensil will burn his hands but due to under responsiveness he will not remove his hand from the warm utensil.

Another e.g., would be the problem in visual processing that will lead to omitting of words or numbers which will affect his academic skills and day to day functioning that requires the reading skills.

This idea is supported by many researches which say that SI occurs due to dynamic influence of sensory inputs occurring as early as in womb which forms the basis of more complex skills like language, emotion etc. Problems at the basic level lead to problems at the higher level. It is found that there is a high correlation between the sensory processing disorder and participation in daily functioning including play. (Bundy et al, 2007; Bra-Shalita et al, 2008; Williames et al, 2009).

SPD is a complex problem affecting all areas of life like development, behaviour, learning, communication, friendships and play. When SPD children try to meet the daily activity their responses may be ineffective and clumsy. Children find their own compensatory ways to deal with it. Mostly child needs assistance through: sensory integration- based occupational therapy (“OT/SI”).

Sensory Integration Therapy (SIT) is a technique of occupational therapy, which provides playful, meaningful activities that enhance an individual's sensory intake and lead to more adaptive functioning in daily life. The emphasis is on improving sensory-motor processing rather than on skill training.

Occupational therapy treats the client by the use of purposeful activity to maximize the independence and the maintenance of health of an individual who is limited by a physical injury or illness, cognitive impairment, a psychosocial dysfunction, a mental illness, a developmental or learning disability, or an adverse environmental condition

From the Sensory Integration theory, the SIT has evolved whose basic idea is that if the sensory system is restored the day to day functioning of the person will also be achieved. The effectiveness of SIT is supported by the past researches and SI theory. 


\section{Sensory Integration Therapy on Social and Self Care Skills in Children with Autism}

It is indicated that improvement in sensory processing enhances participation in home, school, occupational and family activities, improvement in behaviour regulation, including increased engagement and decreased aggression, less need for intense teacher direction, and decreased mouthing of objects. It overall helps in restoring the sensory system and helps the child to participate more in the daily functioning and reduced self injurious behaviour. (Mason \& Iwata, 1990, Robert et al, 2007, Schaaf et al., 2012; Pfeiffer et al, 2011, Schaaf \& Nightlinger, 2007; Zimmer \& Desch, 2012).

\section{METHOD}

The aim accentuates how Sensory Integration Therapy helps in improving some aspects of social and self care skills in children with autism.

\section{Participants}

The sample was confined to ten (3-12 years) according to convenience bases from Delhi and NCR. The regular follow-ups were administered for full three months. It was ensured that they were not receiving any other kind of therapy like speech therapy etc. and are not diagnosed with any other co-morbid disorder.

\section{HYPOTHESES}

- There will be a significant difference in some aspects of social skills within the time frame.

- There will be a significant difference in some aspects of self care skills within the time frame.

\section{TOOL: Goal Attainment Scale (GAS)}

GAS was first developed by Kiresuk and Sherman in 1968. Though old but it provides an excellent individualized, criterion referenced results. It helps in evaluating the functional goals. This approach helps in seeing the extent to which individual goals are achieved. It is used in various fields like rehabilitation, medicine, nursing, social work etc. Goals are formed by the collaboration of client, client family and therapist. Goals formed are specific, measurable, attainable, realistic and timely. It involves defining a unique set of goals for the client who is rated in a scale of 5 ranging from -2 to $+2(-2$ : much less than expected outcome; -1 : less than expected outcome; 0 : expected outcome; +1 : greater than expected outcome; +2 : much greater than expected outcome). Criterion reliability is .60. Reliability is based on the therapist judgement about the impact of intervention, the client present condition and can be increased by involving experienced therapist, training to the therapist about the scale. Inter-rater validity is 


\section{Sensory Integration Therapy on Social and Self Care Skills in Children with Autism}

.88. Validity can be increase by measuring that provides more defensible estimates of post treatment status and employ randomly selected control groups.

\section{Data analysis}

After acknowledging informed consent from parents, a functional assessment was done through the parental interview and observation to know the baseline of the children social and self care skills. According to the baseline, goals were set for the children to achieve in 3 months period which was assigned a rating of -2 to +2 . -2 being the less than what is expected, 0 being what is expected and +2 being more favourable than expected. After the assessment was done, the children were given intensive sensory integration therapy i.e. 3 times a week for 3 months. After the 3 months, again functional assessment was done to rate the predetermined goals. The ratings were converted into overall GAS formula to get a standardised score, was further analysed using Wilcoxon's Signed Rank Test to ascertain any positive difference in the social and self care skills after 3 months of sensory integration therapy.

\section{RESULTS}

\section{Social and Self Care Skills}

The values of mean rank, sum of rank, $\mathrm{Z}$ and significant level for the data is summarised in the table below:

Table 1: Mean Rank of Social and self care skills

\begin{tabular}{|l|l|l|l|}
\hline I. Social Skills & $\mathrm{N}$ & MEAN RANK & SUM OF RANK \\
\hline Negative ranks & 0 & .00 & .00 \\
\hline Positive ranks & 10 & 5.50 & 55.0 \\
\hline II. Self Care Skills & $\mathrm{N}$ & MEAN RANK & SUM OF RANK \\
\hline Negative ranks & 0 & .00 & .00 \\
\hline Positive ranks & 10 & 5.50 & 55.0 \\
\hline
\end{tabular}

Using a Wilcoxon Signed Rank Test on the data $(Z=2.829, Z=-2.823 ; N=10)$, the results were found to be significant at $\mathrm{p}<.005$ level for a one tailed test. This suggests that sensory integration therapy helps in improving the social and self care skills of autistic children.

\section{DISCUSSION}

Sensory Integration theory has given birth to Sensory Integration Therapy whose basic idea rest on the fact that if the sensory system is restored, the day to day functioning of the person will also be achieved. It is indicated that improvement in sensory processing enhances participation in 


\section{Sensory Integration Therapy on Social and Self Care Skills in Children with Autism}

home, school, occupational and family activities. Further it is found that SIT is increasingly used by Occupational therapist for children with developmental and behavioural disorders. (Schaaf et al, 2012; Schaaf \& Nightlnger, 2007; Zimmer \& Desch, 2012).

The social skills which are targeted in the present research are increase in eye contact, decreased undesired behaviour, more interaction with family members / friends, telling own needs, sitting for more duration of time. The results are evidence of the efficacy of sensory integration therapy in improving adaptive behaviour in children. There is improvement seen in some areas of social interaction, approach to new activities, response to holding or hugging and response to movement, decreases in the frequency and duration of self stimulating and disruptive behaviours (e.g., high activity levels, aggressive behaviours); and increase in functional behaviours, such as spontaneous speech, purposeful play, and attention to activities and conversation. (Ayres \& Mailloux, 1983; Linderman \& Stewart, 1999; Mason \& Iwata, 1990; Smith and Bryan, 1999; Smith et al, 2005).

The self- care skills which are somewhat improved by the sensory integration therapy was eating: eating different texture food, eating with hands, putting water in glass and drinking it; then dressing: donning and doffing of socks/pants, put on - remove shoes, wearing caps/ socks and grooming: identifying his own brush, allowing hair cut/nail cut, washing hands, combing hair. The results are supported by past researches that indicated there was a significant change in sensorimotor skills, motor planning, reading related skills, and gross motor skills after receiving SIT program (Benson \& Koomar, 2010; Pfeiffer et al., 2011).

Self care skills are improved as the touch sensitivity is decreased which allows the child to explore the world like touching different texture food/clothes, allowing hair cut/nail cut.

\section{CONCLUSION}

Autism impairs the sensory processing and affects the adaptive behavior of the child. Children avoids eye contact, dislike physical contact, treat people as objects, have no interest/understanding of other people feelings/emotions, never points out things of interest to others - simply stand close to something they want, lack of reciprocity, impaired empathy, unable to understand 'social rules', show little reaction to pain, shows no distress when separated from parents. On the other hand, there are some activities of daily living which a child is expected to fulfil according to his age for example, eating, bathing,, toileting, dressing and grooming which are usually developed till the age of 5 years. Though undoubtedly there are various effective interventions available but the therapy which works on the sensational aspect is sensory integration therapy. Our brain receives sensation (i.e, tactile, vestibular and proprioceptive sense) through our body and surroundings; interprets it and sends a response. The emphasis in therapy is on improving sensory-motor processing rather than on skill training by the use of purposeful activity to maximize the independence and maintenance of health of an individual who is limited by a physical injury or illness, cognitive impairment, a psychosocial 


\section{Sensory Integration Therapy on Social and Self Care Skills in Children with Autism}

dysfunction, a mental illness, a developmental or learning disability, or an adverse environmental condition.

In the present research, Intensive Sensory integration therapy i.e. three times a week for three months with regular follow-ups with parents was found to be conducive in improving some aspects of social and self care skills of children with autism under $3-12$ years of age with repeated rehearsal.

After completion of the task, every researcher is struck with the feeling of some shortcomings i.e., of a small sample. The reason of choosing small sample was the individual attention planned and activities to be rehearsed with each child, simultaneously taking into account the parent's understanding and dedication towards improvement so to reduce absence of the child in the class. In addition a motivational class was also being conducted for parents to help their child in completing the homework assignments. Secondly, few components of adaptive behaviour were accentuated to put less demand on child. Then in the clinical setting, it is crucial to match the uniformity of all subjects in various aspects of day to day functioning. Some children were new to this therapy, therefore little more time was devoted to them as compared to few subjects who somewhat started with the therapy weeks before. In future, further studies in this area can be planned in order to expand the horizon including other components of adaptive skills, increasing the time frame of implementing modality. Moreover, if used with other treatment modalities whose effectiveness cannot be negated in order for improvement in the day to day emotional, social and behavioural functioning of the child.

\section{REFERENCES}

American Psychiatric Association. (2000). Diagnostic and Statistical Manual of Mental Disorders (4th ed., text rev.). Washington, DC: Author.

Ayres, A.J., \& Mailloux, Z.K. (1983). Possible Pubertal Effect on Therapeutic Gains in an Autistic Girl. American Journal of Occupational Therapy, 37, 535-540.

Bra-Shalita, T., Vatine, J.J., \& Parush, S. (2008). Sensory Modulation Disorder: A Risk Factor for Participation in Daily Life Activities. Dev Med Child Neurol., 50(12), 932-937.

Benson, T.A.M., \& Koomar, J.A. (2010). Systematic Review of the Research Evidence Examining the Effectiveness Of Interventions Using A Sensory Integrative Approach For Children. American Journal of Occupational Therapy, 64, 403-414.

Bundy, A. C., Shia, S., Qi, L., \& Miller, L. J. (2007). How does sensory processing dysfunction affect play? American Journal of Occupational Therapy, 61, 201-208. 


\section{Sensory Integration Therapy on Social and Self Care Skills in Children with Autism}

Linderman, T.M., \& Stewart, K.B. (1999). Sensory Integrative-Based Occupational Therapy and Functional Outcomes in Young Children with Pervasive Developmental Disorders: A Single-Subject Study. American Journal of Occupational Therapy, 53, 207-213.

Mason, S.A., \& Iwata, B.A. (1990). Artifactual Effects of Sensory-Integrative Therapy on Self-Injurious Behavior. Journal of Applied Behavior Analysis, 23(3), 361-70.

Pfeiffer, B.A., Koenig, K., Kinnealey, M., Sheppard, M., \& Henderson, L. (2011). Effectiveness Of Sensory Integration Interventions In Children With Autism Spectrum Disorders: A pilot study. American Journal of Occupational Therapy, 65, 76-85.

Roberts, J. E., King-Thomas, L., \& Boccia, M. L. (2007). Behavioral Indexes of the Efficacy Of Sensory Integration Therapy. American Journal of Occupational Therapy, 61, 555-562.

Schaaf, R. C., Hunt, J., \& Benevides, T. (2012). Occupational Therapy Using Sensory Integration to Improve Participation of a Child With Autism: A Case Report. American Journal of Occupational Therapy, 66, 547-555.

Schaaf, R.C., \& Nightlinger, K.M.K. (2007). Occupational Therapy Using a Sensory Integrative Approach: A Case Study of Effectiveness. American Journal of Occupational Therapy, 61, 239-246.

Smith, J.C., \& Bryan, T. (1999). The Effects of Occupational Therapy with Sensory Integration Emphasis on Preschool-Age Children with Autism. American Journal of Occupational Therapy, 53(2), 207-213.

Smith, S. A., Press, B., Koenig, K. P., \& Kinnealey, M. (2005). Effects of Sensory Integration Intervention on Self-Stimulating and Self-Injurious Behaviors. American Journal of Occupational Therapy, 59, 418-425.

Williames, L.D., \& Erdie-Lalena, C.R. (2009). Complementary, Holistic, and Integrative Medicine Sensory Integration. Pediatrics, 30(12), 91-93.

Zimmer, M., \& Desch, L. (2012). Sensory Integration Therapies for Children with Developmental and Behavioral Disorders. Pediatrics, 129(6), 1186-1189. 